\title{
Fãs de ficção seriada de televisão Uma aproximação com os fãs de autores de telenovelas
}

\author{
Maria Carmem Jacob de Souza ${ }^{1}$ \\ UFBA
}

\begin{abstract}
Resumo: A presença dos fãs de programas de ficção seriada na televisão é cada vez mais intensa, estimulando um campo de estudos sobre os fãs de televisão, em particular, sobre as práticas comunicativas de consumo e realização de ficção seriada de televisão. Apresentamos neste artigo os resultados preliminares de um exercício de análise sobre uma das dimensões deste fenômeno, a participação de fãs no processo de construção social da crença no escritor roteirista como autor de telenovelas no Brasil. A pesquisa orienta-se pelos princípios do método de ciência das obras (Bourdieu) e estabelece continuidade com investigações sobre autoria de telenovelas no Brasil. Resultados da análise de duas listas de discussão indicam que a interlocução dos escritores-autores de telenovelas com os fãs e o debate sobre os critérios de qualidade destes programas de ficção seriada tendem cada vez mais a colaborar na formulação e reprodução das crenças na autoria do escritor-roteirista-autor de telenovelas brasileiras.
\end{abstract}

Palavras-chave: fãs; televisão, telenovela; autoria.

Abstract: The increasing rates of the presence of fans of television's fictional series is a stimulating field of study, with particular atention towards the communcational practices of television fans, in connection with the production of fictional series. In this article, we present the preliminary results of an analytical exercise on one of the dimensions of such a phenomenon, i.e., the engagement of fans in the process of social construction of the beliefs on the authorship of brazilian "telenovelas". This research is driven by the principles of the method of the sciences of the the works of art (by Bourdieu), and it establishes a continuity with brazilian researches about authorship of "telenovelas". The results of the analysis of two discussion groups in the internet indicate that the interaction of "telenovelas'" writers/authors with the fans and the debate about the qualitative criteria of such fictional programmes tend to colaborate on the reproduction of the beliefs in the authorship of the screen writer-author of brazilian "telenovela".

key words: fans; television; telenovela, authorship.

1 Professora Adjunta do Programa de Pós-graduação em Comunicação e Cultura Contemporâneas (PosCom). Universidade Federal da Bahia (Brasil). Doutora em Ciências Sociais (PUC/SP). Pesquisadora do CNPq. Coordenadora do grupo de pesquisa A-tevê (CNPq). Publicou, em 2004, Telenovela e Representação social: Benedito Ruy Barbosa e a representação do popular na telenovela Renascer (Rio d Janeiro: e-papers editora). 
Resumen: La presencia de fans de series de ficción en la televisión es cada vez más frecuente, estimulando un campo de estudios sobre los fans y, especialmente, sobre las prácticas comunicativas de consumo y de producción de series de ficción. Presentamos aquí los resultados preliminares de un ejercicio de análisis sobre una de las dimensiones de este fenómeno, la participación de los fans en el proceso de construcción social de la creencia en el escritor-guionista como autor de telenovelas en Brasil. La investigación es orientada por los principios del método de la ciencias de las obras (Bourdieu) y establece una continuidad con investigaciones sobre autoría de telenovelas en Brasil. Los resultados del análisis de dos listas de discusión indican que la interlocución de los escritores-autores de telenovela con los fans y el debate sobre los criterios de calidad de estos programas, tienden a colaborar, cada vez más, con la formulación y reproducción de las creencias en la autoría del escritor-guionista-autor de telenovela brasileña.

Palabras clave: fans, televisión, telenovela, autoría.

Sabe-se que desde as primeiras experiências de produção e consumo de bens simbólicos que almejavam um público amplo e crescente foi preciso estabelecer canais eficientes e permanentes de comunicação com aqueles que representavam este público. A engenharia que produziu esta intensa rede de produtos e iterações, as instituições, grupos e profissionais que a estabeleceram é um estimulante e necessário campo de estudos². Investigações sobre a produção comercial do cinema, do romance-folhetim, da canção, da televisão demonstram essa busca cada vez mais intensa pelo consumidor, espectador, num processo que alguns estudiosos chamam hoje de sinergia dos meios de comunicação de massa, fidelização do consumidor de produtos massivos. Demonstram ainda o crescimento avassalador de segmentos deste público, aqueles que se destacam pelo alto índice de consumo dos produtos, pelo amplo conhecimento das características expressivas e de conteúdo, pelo

\footnotetext{
${ }^{2}$ Apesar de não ter conformado uma avaliação crítica da bibliografia disponível sobre o assunto, sugere-se a leitura de publicações recentes sobre o tema. Consultar as publicações de Henry Jenkins - Textual Poachers: Television Fans and Participatory Culture (Studies in Culture and Communication) e Fans, Bloggers, and Gamers: Media Consumers in a Digital Age. Ver também Fan Fiction and Fan Communities in the Age of the Internet de Karen Hellekson; Theorizing Fandom: Fans, Subculture and Identity (The Hampton Press Communication Series) de Cheryl Harris; The Democratic Genre: Fan Fiction in a Literary Context de Sheenagh Pugh; Fan Cultures (Sussex Studies in Culture and Communication) de Matthew Hills; The Adoring Audience: Fan Culture and Popular Media de Lisa A. Lewis e Fans.
} 
aumento do grau de interação entre eles, consumidores, e demais profissionais envolvidos no sistema. Estes segmentos tendem a ser reconhecidos de um modo geral como fãs.

$\mathrm{Na}$ história da televisão pode-se caracterizar o universo dos fãs a partir do consumo freqüente de um ou mais programas de televisão associado ao aumento de informações sobre o produto, à participação de uma rede de relações associada ao produto, à tendência de se auto-representarem a partir de traços comuns de grupos de fãs e de traços comuns dos programas. Imagina-se que consumidores de produtos seriados sejam mais estimulados a participar de uma rede de comunicação que favoreça a compreensão e o consumo continuado do produto33.

$\mathrm{Na}$ investigação sobre autoria de telenovelas no Brasil surgiu recentemente o interesse de compreender os dispositivos que constituem a crescente interface entre fãs deste produto, as emissoras e os escritores - autores. Das muitas razões para a ampliação das pesquisas nessa área, destacam-se dois aspectos. O primeiro é a evidente ampliação dos canais de comunicação destes escritores com o público, seja nas revistas mais acessíveis, como Minha Novela (editora abril, $\mathrm{R} \$ 1,99$ ), seja na internet. O outro aspecto é a ampliação do mercado de produção e consumo das telenovelas que está absorvendo um público cada vez mais amplo, um número cada vez maior de emissoras, um conjunto cada vez mais expressivo de escritores, roteiristas, boa parte deles, fãs da ficção seriada mais popular do Brasil.

Neste momento embrionário da pesquisa ${ }^{4}$, os fãs serão definidos como consumidores assíduos de telenovelas e de produtos associados (encartes de jornais, revistas sobre televisão, programas de televisão, programas de rádio, entre outros produtos). Participam com gosto de rodas de conversa sobre telenovelas, de grupos e fóruns de discussão para trocarem informações sobre o produto, sobre a experiência

\footnotetext{
3 Espera-se poder em futuro próximo comparar os sistemas de comunicação que favorecem a fruição e o consumo de produtos televisivos seriados com os sistemas de comunicação para o consumo de programas de ficção televisiva não seriada. Espera-se ainda poder identificar semelhanças e diferenças nos sistemas de comunicação entre produtos de ficção seriada televisiva com outros produtos seriados de outros meios de comunicação, tais como histórias em quadrinhos, romances, filmes.

$4 \mathrm{O}$ estágio atual da pesquisa não permitiu ainda um conceito preciso de fã. Registra-se aqui esta ressalva e a informação de que este conceito está em construção.
} 
da fruição, entre outros assuntos. Tendem a, de um modo geral, estabelecer vínculos afetivos intensos e duradouros tanto com personagens, atores - atrizes, quanto a avaliar com entusiasmo o processo do desenrolar da narrativa. Fãs acumulam experiências de apreciação e conhecimentos sobre o produto adorado. Muitos deles manifestam a experiência apaixonada de consumo e participam ativamente de redes sociais para compartilhar sensações, sentimentos, sentidos gerados nos modos de "ver e usar" as telenovelas

No caso da telenovela no Brasil tem-se notícia de fãs desde meados dos anos sessenta quando as telenovelas já conquistavam corações fiéis traduzidos em índices de audiência que foram tornando estes programas nas décadas seguintes um dos produtos comerciais mais promissores da televisão. Desde então, têm-se notícias de modos variados de expressão dos fãs. Canais de comunicação criados com os atores e atrizes, com os personagens preferidos, com as emissoras e até mesmo com os escritores $^{5}$. Cartas, contatos diretos e, atualmente, e-mails, listas de discussão, comunidades do orkut e outras ferramentas também têm sido usados.

Grupos de fãs podem adquirir notoriedade e reconhecimento para estabelecerem canais de interpelação e interlocução com um dos objetos adorados: os escritores autores de telenovelas ${ }^{6}$.

O acompanhamento da atuação do moderador da lista novelas ${ }^{7}$ e da dinâmica de funcionamento dessa rede permitiu observar que neste fórum as definições de telenovelas e os critérios de qualidade do produto foram discutidos. O reconhecimento do roteirista-escritor responsável pela telenovela como autor não era colocado em dúvida.

5Sobre este assunto ver Resende e Klagsbrunn (1991); Hamburger (2005); Ortiz et al. (1989). ${ }^{6} \mathrm{O}$ moderador da lista novelas, por exemplo, relatou que em 2005 ocorreu um aumento da participação de escritores consagrados como Glória Perez e Carlos Lombardi. Deixaram de observar a lista para intervirem, dando opiniões.

7 Criada e moderada por Alexsandro Oliveira, que durante os anos de 2004 e 2005 foi bolsista de iniciação científica (CNPq) da pesquisa por nós coordenada, na Faculdade de Comunicação, Universidade Federal da Bahia. 
Esta certeza do lugar da autoria remete aos resultados da pesquisa sobre a construção social do autor nas telenovelas brasileiras ${ }^{8}$.

O exame dos princípios de definição da autoria historicamente formulados pelos agentes envolvidos na produção das telenovelas no Brasil - observados por meio de documentos, discursos, críticas revelou definições que anseiam por reconhecimento e consagração daqueles que participam na elaboração deste programa de televisão e dos consumidores. As proposições formuladas por Bourdieu indicam que estas definições estão inseridas num campo de lutas que envolvem as emissoras e as outras instituições e agentes que interferem na constituição dos sistemas de avaliação-valorização de telenovelas e dos seus realizadores (profissionais organizados num sistema hierárquico que participam da elaboração da telenovela). A definição de autoria de telenovela surge, então, a partir das histórias de campos de telenovelas. Em suma, as disputas em torno das definições de autoria das telenovelas no Brasil têm facetas e particularidades decorrentes da história das experiências de elaboração da própria obra, telenovela, na sociedade brasileira.

Até o momento, é possível dizer que no estado atual da história do campo de produção, distribuição e consumo da telenovela no Brasil, os profissionais que detêm a maior capacidade de decisão e a maior responsabilidade diante do produto final são, além dos representantes das emissoras (os produtores), o diretor geral e o escritor, estando ambos, em geral, contando com mais de um colaborador. É possível afirmar, também, que existe uma tendência a considerar o escritor responsável como aquele que detém o poder de conformar uma marca particular na telenovela reconhecida como legítima marca de autoria.

Os fãs, seguindo essa perspectiva analítica incentivada pelo conceito de campo, habitus e autoria em Bourdieu, fazem, pois, parte da cena do campo da telenovela, tanto como consumidores quanto como realizadores.

Este artigo apresenta os resultados iniciais de uma reflexão sobre a autoria das telenovelas brasileiras a partir do ponto de vista de fãs de duas listas de

\footnotetext{
8 Faz-se referência a pesquisas realizadas sobre a construção social da autoria nas telenovelas, o caso de Benedito Ruy Barbosa e Luiz Fernando Carvalho (1993 a 2002, Horário das 21 horas, TV Globo). Apoio do Programa de Pós-graduação em Comunicação e Cultura Contemporâneas da Universidade Federal da Bahia e do CNPq/br (desde 2003).
} 
discussão:

novelas@yahoogrupos.com.br9

roteirostelevisao@yahoogrupos.com.br1o.

\section{Fãs de telenovelas}

Partimos da premissa que a ampliação da autonomia do campo da telenovela no Brasil ${ }^{11}$ influenciou a força da representação da autoria concentrada no autor escritor, roteirista responsável pela telenovela, apesar do sistema coletivo de produção audiovisual ser gerido pelo diretor geral e pelo produtor e deste produto comercial estar voltado ao grande público ${ }^{12}$. Exemplos recentes ilustram a presença marcante desta representação. O primeiro a ser lembrado é a substituição do Diretorgeral da telenovela América (TV Globo, 2005) justificado publicamente pelas diferenças e discordâncias com a roteirista-autora, chamada pela imprensa e diletos do gênero como escritora ${ }^{13}$. Um outro episódio foi a demanda por um "escritor", autor de sucesso do horário das sete da TV Globo, para enfrentar problemas de

\footnotetext{
9 Moderada por Alexsandro Oliveira. A base de dados para a análise preliminar baseia-se nas mensagens registradas em nosso arquivo de fevereiro de 2004 a outubro de 2006. Não fizemos parte da lista, o material foi repassado pelo moderador. Em 18 de janeiro de 2007 contava com 192 associados. Esta lista foi criada em junho de 2000. No período de 12 a 18 de janeiro foram emitidas 115 novas mensagens. O período examinado pela pesquisa, fevereiro de 2004 a janeiro de 2007reuniu 1200 mensagens selecionadas pelo moderador que foram classificadas por emissor e conteúdo. Neste período estima-se que mais de 6000 mensagens foram emitidas. Consultar o endereço da lista.

${ }^{10}$ Moderada e criada por Leonardo de Moraes. A primeira leitura das mensagens da lista tem como base de dados aquelas emitidas durante os meses de dezembro de 2005 a janeiro de 2007. Nesse período fazíamos parte da lista. A lista foi criada em 8 de novembro de 2005 com o nome de roteirostelenovelas@yahoogrupos.com.br. Em marco de 2006 o moderador alterou para o nome atual roteirostelevisao. Em 18 de janeiro de 2007 contava com 646 associados. No período de 12 a 18 de janeiro contou com mais seis associados e 51 mensagens. O período examinado pela pesquisa reuniu 3000 mensagens classificadas por emissor e conteúdo. Consultar o endereço da lista.

${ }^{11}$ Consultar a reflexão realizada por Souza (2004) e Ortiz e Ramos (1989) sobre o campo da telenovela no Brasil.

$12 \mathrm{O}$ processo de construção social da autoria nas telenovelas está mais amplamente descrito em Souza (2004b).

${ }_{13}$ Consultar artigo de Simone Mousse, "depois do Vendaval”. Jornal o Globo, 17/06/2005.

“....A autora admite que as críticas recebidas na primeira fase, dirigida por Jayme Monjardim, que se afastou há dois meses, eram justíssimas. - Jayme quis contar outra história que não a que estava escrita. Não podia dar certo. A minha novela é a que está no ar agora.(...)"
} 
audiência na telenovela Bang-Bang, para muitos agravados com a saída do autorescritor logo nas primeiras semanas ${ }^{14}$.

O conceito de campo da telenovela tem sido valioso para examinar o fenômeno da autoria. Campo da telenovela diz respeito aos agentes, instituições e grupos que participam do processo de elaboração, circulação e consumo das telenovelas e formulam definições de suas práticas num contexto desigual de distribuição do poder e de conformação das bases que sustentam definições legítimas capazes de formular e reproduzir disposições mentais incorporadas que se traduzem em senso prático e sistema de crenças. As crenças validam a participação no campo, a identificação e valorização do que deve ser importante de fazer e pensar quando se faz parte do universo de práticas que constituem o campo da telenovela. A crença de que existe uma definição legítima de telenovela, que se pode e deve realizar telenovelas que serão reconhecidas por uma aferição de suas qualidades formulado pelos que fazem parte do sistema.

As crenças incorporadas pelos agentes são, segundo Bourdieu (2005, p.258) a base para a illusio necessária que torna possível a existência e a reprodução do campo. Como imaginar o tempo dedicado, a expectativa entusiasmada dos roteiristas que desejam ser reconhecidos pelo público, pelas emissoras e pelos profissionais respeitados sem a illusio necessária que move cada um deles?

O valor de cada telenovela de cada escritor surgirá nesta história de práticas de telenovelas que envolvem uma diversidade de agentes e instituições, num sistema de concorrências marcado pela desigualdade na distribuição de poder. Agentes que classificam e definem o que fazem, o sistema de avaliação que servirá de lastro para o reconhecimento e a consagração dos produtos gerados. Lembrando Bourdieu, “... o que sobrevém no campo" deve ser compreendido a partir da "história específica do

\footnotetext{
14 Destacamos a coluna de Daniel Castro da Folha de São Paulo em 7 de dezembro de 2005. Tratando do "faroeste Lombardiano", Castro insinua que problemas na equipe de escritores relacionam-se ao "abandono" de Mario Prata que não resguardou a equipe dos erros. Lombardi, no mesmo dia, comentou esta assertiva do colunista na lista Novelas permitindo inferir que não considera que a equipe tenha errado na abordagem melodramática, apenas não ampliou e consolidou as estratégias de comicidade. O interessante é a importância que Lombardi deu aos leitores e comentadores da lista, resguardando suas proposições e ao mesmo tempo conduzindo seus leitores para determinados pontos de vista sobre a análise de telenovelas, indicando a leitura de críticas da "Bang Bang" de outros Jornais.
} 
campo, dava vez mais difícil de deduzir diretamente do estado do mundo social ...” (2005, p.274). No caso das telenovelas, por exemplo, tem-se as disputas tanto pelas definições dos seus aspectos gerais quanto dos específicos: das características de extensão e serialização aos modos de atribuir títulos, construir expectativas no primeiro capitulo, entre outros. Aspectos que remontam a uma lógica interna própria do campo da telenovela, das "heranças" inscritas na sua história, “..no estado de coisas ...que delimita o pensável e o impensável e abre o espaço das perguntas e das respostas possíveis" (p.274).

O que Bourdieu nos ajuda a perceber é que o valor que se atribui ao escritor como autor, as qualidades atribuídas a uma emissora e as telenovelas não dependem apenas dos interesses dos envolvidos. Afirma que é neste universo de práticas e saberes chamado campo que são produzidos estes interesses que fazem parte de um universo de crenças capaz de definir e legitimar o "valor da obra de arte [telenovela] como fetiche ao produzir a crença no poder criador do artista [no caso da telenovela os realizadores envolvidos e o autor-escritor]" (p.259).

Sabemos que o método da ciência das obras formulado por Bourdieu foi mais amplamente usado para examinar experiências artísticas reconhecidas no campo da produção cultural como "puras", voltadas para especialistas, conhecidas pelo maior grau de autonomia diante das pressões econômicas, políticas e religiosas. O livro as regras da arte (2005) explora os resultados da aplicabilidade do método para examinar a literatura, em especial o romance e a poesia, comparando-a sobremaneira com o campo musical e o campo das artes plásticas. Os conceitos de campo, habitus, trajetória, espaço de possíveis explorados em tantos outros livros e artigos do autor, de seus colaboradores e de outros pesquisadores reafirmam, todavia, que as premissas gerais do método são também relevantes para examinar expressões artísticas populares, massivas, midiáticas, como é o caso da teledramaturgia, em particular, a telenovela.

O fenômeno da reflexividade em um momento histórico do campo da telenovela de maior grau de autonomia, pensado a partir desta perspectiva analítica, gerou a pergunta sobre o papel dos fãs que partilham e ao mesmo tempo fomentam a crença no roteirista-escritor-autor de telenovelas no Brasil. 
Uma maior autonomia dos campos, mesmo os voltados para a produção comercial, tende a gerar um "movimento para uma maior reflexividade...uma espécie de volta crítica sobre si, sobre seu próprio princípio, seus próprios pressupostos” (p.273). Este movimento associa-se a outros como a tendência de uma exigência maior para "entrar no campo", em especial, "o domínio pratico das aquisições específicas de toda a história do gênero [telenovela] que estão objetivadas nas obras passadas e registradas, codificadas, canonizadas por todo um corpo de profissionais da conservação e da celebração...” (p.273).

Para examinar o campo da telenovela exigi, pois, identificar: a) domínios ou habilidades necessárias para participar no campo; b) como são adquiridos; c) quais as telenovelas que fazem parte desse repertório de obras passadas e de que modo estão registradas; d) quais são os agentes reconhecidos como profissionais da conservação e da celebração legitimados para codificar e canonizar telenovelas.

Neste momento não vamos aprofundar esses aspectos salientados. O que se pretende é apontar que determinados fãs assumem essas funções de colaboração na formação das habilidades ou "domínio prático e teórico" (p.274) facilitadoras da entrada no campo, da criação de fóruns de discussão dos critérios legítimos de elaboração de uma boa telenovela, de construção de indicadores das melhores telenovelas já exibidas. Participam, pois, da função de formulação da herança a ser inscrita no campo, das crenças dos sistemas de reconhecimento e consagração tanto das telenovelas quanto daqueles que fazem parte da sua elaboração. Além disso, podemos dizer que criam um espaço de definições e reconhecimento de consumidores e realizadores de telenovelas no espaço dos consumidores. Uma rede de consumidores especializados reconhecidos por outros passa a existir configurando as possibilidades de criação de um patrimônio particular, importante numa trajetória ascendente, que vai se convertendo no que Bourdieu denomina de capital social, capital cultural e capital especifico do campo. Pode-se observar, então a gestação ou trajetória ascendente de fãs que poderão assumir posições significativas na formação das crenças demarcadoras da illusio do campo. Um espaço de formação e reprodução de representações sobre uma dimensão que tende a valorizar obras e realizadores: a existência do autor. 
Esta reflexividade supõe, em suma, a atuação no campo de agentes especializados responsáveis pela revisão crítica de modos de fazer e pensar telenovelas. Estratégias e recursos objetivados em manuais, instâncias de formação e repertório capazes de estabelecer quais devem ser consideradas as telenovelas exemplares, os modos de fazer telenovelas que tenham maiores condições de garantir reconhecimento e consagração dos realizadores, dos pares especialistas, dos críticos e do público. $\mathrm{O}$ ato da reflexividade crítica das obras decorre, portanto, de estratégias e modos de fazer e pensar incorporados pelos agentes da realização de telenovelas e de agentes e instituições de outras instâncias, como a do consumo, que permitem reconhecer e rememorar um conjunto de telenovelas realizadas no Brasil e alhures. Enfim, a reflexão crítica sobre as obras culturais populares, no sentido de massivas também está associada a um sistema de formação de realizadores e especialistas.

Os dados sobre a história do campo da telenovela no Brasil permitem investigar, enfim, qual a relação entre o nível de rigor e exigência da revisão crítica, ou seja, do tipo de reflexividade existente no campo, com o grau de exigência posto pelas "condições de entrada no campo". A hipótese no atual estágio de reflexão sobre o assunto é a de que quanto mais difíceis, codificadas, institucionalizadas as regras e condições para se tornar um roteirista, diretor ou ator de telenovela (etc.) maior a demanda dos interessados em posições de reconhecimento pela ampliação do repertório especializado acumulado na história do campo, por um capital social mais amplo, por capitais específicos mais valorizados.

Sendo assim, a depender da importância da função do roteirista na equipe de produção das telenovelas, ter-se-á uma exigência maior ou menor para acumular, exercer e testar as habilidades que se espera de um roteirista deste tipo de produto comercial. Se o autor-escritor é muito importante no processo, espaços de formação especializados de roteiristas tendem a surgir, apoio de escritores consagrados se torna essencial, apresentar o maior número de resultados de sucesso nas parcerias com os escritores-titulares tende a ser mais exigido.

Apesar do pequeno grau de autonomia do campo da telenovela no Brasil, vale salientar que espaços de conversações, como as listas de discussão e 
comunidades do orkut se multiplicaram ${ }^{15}$. Lembrar da criação, em 2000, da Associação brasileira de roteiristas profissionais de TV, cinema e outras mídias ${ }^{16}$. Estas instâncias exprimem princípios de saber práticos, lógicas compartilhadas que tendem a identificar, ampliar e consolidar estratégias de definição do valor positivo, da "boa" qualidade da telenovela e dos escritores. Exprimem definições que legitimam o realizador de telenovela que será reconhecido e premiado como autor.

Um outro ponto freqüente na pauta de conversações sobre a autoria é as estratégias narrativas, sonoras, visuais, cênicas, sensoriais consideradas criativas, inovadoras, eficientes nas telenovelas. Neste contexto, quais são os princípios de definição de telenovela mais exemplares, permanentes e compartilhados entre autores e fãs sobre a qualidade e a autoria das telenovelas no Brasil?

Rememoramos que o interesse central deste artigo não é responder essas pergunta, é, antes de tudo, formulá-la. O que se almeja é apresentar reflexões preliminares sobre um dos especialistas fomentadores da reflexividade no campo da telenovela, os fãs. No caso dos fãs das listas de discussão examinadas, dois aspectos curiosos sobre a crença na autoria serão destacados. $\mathrm{O}$ primeiro diz respeito às implicações da interlocução entre autores/ escritores e o público-fã no sistema de avaliação da ressonância das telenovelas no público e na formulação da definição legítima de quem deve ser o autor.

O outro salienta a presença de fãs cada vez mais empenhados no processo de formação de roteiristas de ficção audiovisual para TV, em particular, telenovelas. Nestes casos, estes e outros canais de comunicação com escritores e outros fãs tendem a ampliar os espaço de formação do habitus de escritor de telenovelas, da

\footnotetext{
15 Tem-se a impressão que este advento na internet esteja associado a outros fenômenos, que devem posteriormente ser investigados: a crescente racionalização industrial do sistema de produção e distribuição; a expansão dos profissionais de comunicação e áreas afins que podem ingressar no campo da telenovela; o reconhecimento nacional e internacional da boa qualidade das telenovelas brasileiras; o reconhecimento das telenovelas e realizadores por parte do campo científico; o aumento de fãs no conjunto dos jovens que cresceram com as telenovelas e adolesceram com a Internet e seus sistemas de comunicação e relacionamento. ${ }^{16}$ A associação nasceu na Internet a partir de um protesto contra a falta de créditos de roteirista num programa humorístico da TV Globo, agravado pela notícia de que este diretor jamais escrevera uma linha de roteiro (disponível em www.artv.art. br acesso em 18.01.2007).
} 
crença no autor roteirista, uma posição no campo cada vez mais difícil de exercer e de ser reconhecida.

\section{Interlocução entre escritores e fãs}

Mecanismos de identificação e interpretação das sensações, emoções e sentidos produzidos pelas audiências das telenovelas têm sido desenvolvidos pelas emissoras, pelos pesquisadores, pelos realizadores. Estes recursos são necessários pela natureza do produto. Telenovela precisa atender o maior número de expectativas de um conjunto amplo e diferenciado do público e ao mesmo tempo atender as expectativas econômicas e financeiras das emissoras e demais agentes do campo publicitário ${ }^{17}$.

Os escritores, em muitos depoimentos, alertam para o fato dos dados quantitativos não serem suficientes para conhecerem a ressonância mais profunda da telenovela ${ }^{18}$. Os dados qualitativos gerados pelos grupos de discussão são mais eficientes, mas todos os escritores, de um modo ou de outro, precisam criar seus próprios indicadores e sistemas de aferir o que o público está compreendendo, sentindo, gostando ${ }^{19}$. Estas informações, dizem os escritores, ajudam no processo de realização, pois escrever para tantos, tão diferentes, por tanto tempo, requer bússolas que os ajudem a singrar por rotas conhecidas de mares surpreendentes.

Contexto que ajudou a proliferar listas de discussão reconhecidas como "sérias"

\footnotetext{
17 Os estudos de Hamburger (2005) e Priolli e Borelli (2000) são assaz esclarecedores. ${ }^{18}$ Apesar dos mais sofisticados sistemas de medida da audiência, as breves entrevistas publicadas em 2006, no caderno 2 do Jornal O Globo com Silvio de Abreu (3 jan), Gilberto Braga ( 5 jan), Antonio Calmon ( 7 jan) e Maria Adelaide Amaral (6 jan) reafirmam que os resultados do Ibope ilustram e indicam, mas não têm o poder da definição sobre as estratégias usadas e muitas vezes mais atrapalha que ajuda o processo da escritura.

19 Inúmeros podem ser os exemplos, mas vamos ficar com Gilberto Braga (Globo, 5 de janeiro de 2006): "Você acompanha o Ibope minuto a minuto? - Deus me livre! Nem pensar! Acho demoníaco e irrelevante para o meu método de trabalho, que é intuitivo. Se a novela está agradando ou não chega logo aos meus ouvidos, sem essa tortura."

${ }^{20}$ Seriedade identificada pelo controle rigoroso dos membros da lista, pelo cuidado com as fontes e com o conteúdo das mensagens. As disputas, mesmo que veladas, entre os participantes da lista denotam a necessidade de cada participante ser reconhecido como detentor de maior volume de informações, de contatos com escritores consagrados, de ser admirado pelo poder de conseguir boas entrevistas, de gerar discussões interessantes a partir
} 
interessam os escritores porque permitem observar a ressonância das telenovelas em fãs que se dispõem a falar com propriedade do que sentem, compreendem e esperam do produto ${ }^{21}$.

O escritor-autor interessado terá acesso permanente a uma audiência assídua, cuidadosa, crítica e especializada que domina detalhes da longa história do campo da telenovela. Para exemplificar, transcrevemos trechos de mensagens de participantes mais freqüentes ${ }^{22}$.

Sobre a avaliação do escritor num sistema comparativo de suas obras...

"Gilberto Braga é um autor que amo e que mesmo quando erra "Pátria minha" - faz com categoria. O que mais gosto do autor? Provavelmente a criatividade em bolar os planos que o grupo do bem e o grupo do mal (obrigado, Diego, pelos apelidos) armam uns contra os outros e a forma como desmascará-los. Sempre tomamos uma boa dose de conhecimento com novelas gilbertobraguianas (ele me ensinou o que era exame de DNA) e temos festas e boas soluções para seus assassinatos misteriosos."

Lista novelas. Participante comenta em 10.12.2005 os "tops de G. Braga"

Participante da lista Novelas ${ }^{23}$ escreve em 17 de outubro de 2005 para Glória Perez durante a "crise" com a direção geral (Jayme Monjardim). Pede cópia da Sinopse para "ler como os personagens foram caracterizados para entender a questão da direção”. Gloria Perez, no mesmo dia comenta:

"o autor de novelas não tem o privilégio que o autor de teatro e de cinema tem: seu texto não chega ao público. No teatro, como no

de críticas de telenovelas que escreveu ou leu. Dispositivos que tendem a manter a seriedade dos conteúdos veiculados e da rede de relações criadas.

${ }^{21}$ Os participantes da lista conhecem e lembram com detalhes de mais de uma telenovela de cada escritor(a), esperam com ansiedade, acompanhando de perto, a produção das seguintes. Torcem pelo retorno do(a) escritor(a) preferido(a). Avaliam o primeiro e último capítulos detalhadamente. Examinam os níveis de audiência e a ressonância na imprensa. Fãs desta natureza tendem a acompanhar cada passo das telenovelas, podendo ver os capítulos preferidos mais de uma vez. Gravam muitos capítulos promovendo encontros para rever as telenovelas. Novos mercados de trocas são estimulados, seja pelo interesse de compartilhar com outros fãs, seja por motivos econômicos.

${ }^{22} \mathrm{O}$ material de análise caracteriza-se pelo volume e extensão, não sendo possível trazer muitos exemplos neste artigo.

${ }^{23} \mathrm{Na}$ lista novelas a atuação de Gloria Perez e Carlos Lombardi é exemplar. Eles comentam as avaliações dos participantes, respondem críticas, fomentam debates, fazem denúncias, esclarecem o processo de criação e os problemas que enfrentam. 
cinema, você pode ler o roteiro e diferenciar, nitidamente, um bom texto de uma má encenação. Na televisão você não tem o texto, então é preciso ter o olhar mais treinado para perceber de onde vem o erro. Vou lhe mandar, a titulo de exemplo, um trecho da descrição da personagem SOL na sinopse. Quando você escreve uma personagem, a pergunta primeira é: o que é que essa pessoa quer? No caso, a Sol tinha o sonho, a ilusão que é de tantos brasileiros hoje, de conquistar o sonho americano. Bom, o objetivo de uma personagem, como de uma pessoa, tem de estar em correspondência com seu temperamento. Um alpinista não pode ter medo de altura, senão não será um alpinista. Será, no máximo, alguém que sonha com o que não tem condições de fazer. Do mesmo modo, uma pessoa que se propõe largar seu país, atravessar um deserto, viver essa aventura de recomeçar a vida num país estranho, sem nenhuma qualificação, nenhum preparo, tem que estar movida por uma "paixão", por uma certeza. Tem que ter força e coragem, senão não faz. Por isso, a personagem é descrita assim na sinopse: SOLvital, impulsiva, impetuosa, batalhadora, extrovertida, alegre. Honesta e de bom caráter. Tem "atitude", personalidade forte, curiosa e inquieta. Pensa grande, não se contenta com pouco. É determinada e forte, gosta dos desafios e tem coragem de correr os riscos que se apresentem para ir atrás dos seus sonhos. O que a atrapalha é o temperamento fantasioso, sob o qual ela não tem controle, e que costuma dominar seu senso de realidade. (...) Sua meta de vida não é tão definida nem tão objetiva quanto a de Tião: Tião quer ser o melhor peão do rodeio. Tem talento e se dedica a se tornar o melhor. A realidade está a seu favor. O mesmo não se pode dizer em relação a nossa protagonista. Ela não pára para pensar se seu sonho é viável ou não: a realidade não está a seu favor, mas SOL não acredita no impossível e confia muito mais na sua intuição que na realidade. É do tipo capaz de atravessar mares e montanhas, de correr todos os riscos por causas nitidamente perdidas. E nunca se deixa abater. Enfrenta todas as desventuras convicta de que as tempestades sempre passam e dias melhores virão: é só saber resistir. E ela resiste como ninguém. Tem sempre forças para levantar e dar a volta por cima. Não é de ficar se lastimando nem caindo em depressões, mesmo nos piores momentos, porque as pessoas que estão como ela, no auge de uma luta onde arriscam tudo, não podem se permitir fragilidades. Então ela engole o choro, engole as mágoas e segue adiante, sempre juntando os seus cacos com uma dignidade comovente. Tem "nariz em pé" e uma verdadeira vocação pra ser feliz. Acredita que cada um escreve a própria história, e por isso mesmo tem tanta certeza de que tudo só pode terminar muito bem, porque depende mais dela do que as circunstâncias de que seja assim. No ar, o que se viu foi uma SOL que chorava o tempo todo e contrariava completamente a descrição da sinopse! Frágil. Faltava nela aquela certeza, aquela paixão que faz com que a gente acredite na sinceridade dos sonhos alheios, por mais equivocados que eles sejam. Aquela SOL não atravessaria uma rua, muito menos um deserto.Mal vestida, com aspecto de suja e pintada de marrom. A mulher que mulher nenhuma queria ser e por quem homem nenhum se apaixonaria.Mandavam que ela chorasse toda vez que olhava Tião, toda vez que dizia eu te amo! Ninguém 
nesse mundo quer um amor que faz chorar. Amor tem que ter tesão e alegria. Por isso as pessoas amam Dinho e Neuta, Ed e Sol! A culpa é da atriz? não! A atriz submeteu-se à direção, como qualquer profissional o faria. Portanto, ninguém merece menos do que ela as criticas que lhe foram feitas. Quer um exemplo cinematográfico? Gilda! Gilda exige uma mulher sensual para representa-la. Se o diretor tivesse retirado a sensualidade da Rita H. de cena, mandado que ela chorasse em cada cena, que fosse frágil e desmilinguida, certamente nós nem estaríamos falando desse filme ainda hoje! Bom, isso foi só um pequeno exemplo das atrocidades cometidas."

Gloria Perez. [Lista novelas] em 17 de out de 2005.

\section{Fãs e escritores construindo a crença na autoria de telenovelas}

As riquezas e minúcias das análises de alguns fãs mostram um processo de formação enquanto crítico e realizador. Na "lista Novelas" o interesse em se profissionalizar é sugerido nas mensagens, mas a tendência maior está na formulação da crítica. Na "lista roteiros", como não podia deixar de ser, o desejo de ser roteirista é o que agrega os fãs.

Nestes fóruns observamos pontos de vista que postulam as qualidades das telenovelas, os acertos e erros. Espaços de aprendizado e de reafirmação de critérios que são formulados como princípios que devem orientar este campo de práticas, que devem ser incorporados pelos especialistas fãs e por aqueles que desejam se profissionalizar. Em muitas ocasiões, em ambas as listas, os escritores foram chamados a depor, a intervir, a apresentar posições. No caso da "lista roteiros" a preocupação mais evidente com os roteiristas leva os participantes a disponibilizarem roteiros e sinopses. Além disso, indicam e comentam livros e artigos, publicam entrevistas coletadas em outros meios, clippings e críticas de roteiros de outros ou de participantes da lista que assim o desejarem. Busca-se garantir um espaço de reflexão e de formação de roteiristas de telenovelas.

Segue um depoimento ilustrativo sobre a formação de modos de ver e fazer telenovelas dos fãs e dos escritores que cultivam os princípios e práticas da crença que o escritor- roteirista responsável é o autor das telenovelas. Autoria como princípio que representa a necessidade imperiosa da ampliação da autonomia dos realizadores nos campos midiáticos da produção cultural. 
Manifestação de um dos interesses em jogo no campo do audiovisual Televisão ou cinema: o poder de ampliar a autonomia do processo de criação dos escritores-roteiristas no mundo comercial da ficção audiovisual, que se sabe limitado em muitas situações onde o poder mais premente tem sido dos diretores e ou produtores.

Em mensagem de 12 de janeiro de 2007, temos o depoimento de um colaborador da novela "Pé na Jaca" (Carlos Lombardi, TV Globo, 19h, 2007) sobre a função dos roteiristas de telenovela na formação daqueles que esperam um dia poderem ser reconhecidos como autores responsáveis pela equipe de colaboradores. Depoimento da presença da illusio que ao mesmo tempo afirma a crença na posição do autor e o deleite da ação criadora, mesmo em condições de alta concorrência e acentuada pressão pelo sucesso comercial e de público. Este depoimento mostra a satisfação de colaborar na formação de roteiristas iniciantes. Pormenoriza como a formação se dá durante o oficio, salienta a diversidade de origens de formação dos escritores afirmando que não é a origem profissional, mas as habilidades incorporadas e os capitais específicos adquiridos ao longo da trajetória dos escritores que podem favorecer posições de consagração e o reconhecimento de autor.

Com a palavra, Maciel:

“a TV é como aquelas corporações da Idade Média onde se aprende um ofício. As pessoas vão se juntando num estúdio sem janela e vão fazendo e aprendendo na marra, e se surpreendendo sempre. Estas pessoas sabem o que fazem. Por outro lado, quem critica de fora, não sabe até hoje, justamente por não terem pego esse ofício - só quem tem uma intimidade com o lado de dentro da indústria sabe quanta mentira é publicada em praticamente todos os jornais e colunas, críticas cegas e preconceituosas, invenções para preencher espaço...No caso do Lomba [Carlos Lombardi], falando nos mestres, ele fez Comunicação e Língua Portuguesa na USP, Antônio Abujamra diz que ele e Tadeu Jungle eram seus melhores alunos, "os malditos CDFs", tanto que o levou à Cultura depois - mas foi lá que o Lombardi diz ter aprendido, trabalhando com o próprio Abu, depois com o Silvio [de Abreu] que dirigia os telecursos e viria a ser seu chefe em Jogo da Vida e Guerra dos Sexos, depois o Cassiano, etc. Com o Silvio foi mais ou menos a mesma coisa, ele fez a ECA [USP] focado em cenografia para ser ator(!), mas aprendeu a dirigir olhando o [Carlos] Manga cortar no switcher, palpitando, e depois quis ser escritor-noveleiro enquanto lia os roteiros que atuava, da Ivani [Ribeiro], e ficava bobo com a forma como ela urdia histórias. Vai por aí. Dos autores famosos, tirando Lombardi por coincidência 
segundo ele mesmo, não conheço ninguém que tenha aquela formação que um roteirista espera - Gloria [Perez] é historiadora, Gilberto [Braga] era professor de francês, Aguinaldo [Silva] era jornalista-policial, Manoel Carlos era diretor do Fantástico, Euclydes [Marinho] era fotógrafo, [Antonio] Calmon era diretor do Cinema Novo. E de novo, a vida vai levando. Cada um teve as famosas portas-abertas, e sem nenhum favor, por acontecimentos esporádicos mas definitivos e indefinidos, não só a coisa da pessoa certa na hora certa, mas também o fato de estarem já no lugar que gostavam, insisto, não em termos de profissão, mas de ambiente. Quando alguém tem talento, ninguém segura. Portanto, não há regras - assim como também não quis dizer que não vale a pena brincar de fazer roteiros, tudo vale a pena como prática, até um tombo na escada ou uma desventura amorosa; ...Começando "artesanalmente", acho que burilamos mais a nossa identidade, o nosso talento à prova, ...especificamente em TV o mais provável é que não só quem te contrate goste do seu mundo, como você tenha que entrar também no mundo dele, falar a língua dele, porque por mais que uma novela hoje tenha de cinco a sete colaboradores, há sempre o pai da criança - e se tudo não correr do jeito que ele pensa, espera, sente e fala, os personagens degringolam, a trama sai do lugar e o público sente um ruído... O bom colaborador precisa sim estar atento a isto; não adianta fazer diálogo do Gilberto [Braga] numa novela do Aguinaldo [Silva] e vice-versa, sem demérito a ninguém. Estilo é importante e faz bem. O Manoel Carlos fala "já tomou o café da manhã, que o trânsito no Leblon hoje estava uó" enquanto o Gilberto [Braga] mesmo fala "olha o desjejum que essa geléia de morango eu importei que estava uma coisa!" - e é exatamente isto que fez a Globo ser o que é, a diversidade. ...Esse grupo tem me feito acreditar mais e melhor na minha geração, que ainda considero meio perdida, e agradeço por isso. Precisamos usar a internet pro Bem, mesmo, porque um dia a indústria vai precisar de carne nova, com certeza, tirando o Lombardi que tem 48, todos os outros que citei acima, ou quase todos, já passaram dos 60 , e tirando esse fator do vício, também é verdade que novela cansa e qualquer hora muita gente vai ter que implorar e abrir mão de contratos milionários pelo simples prazer de se aposentarem pra curtir a vida e as coisas da vida. E quando isso chegar, eu gostaria muito que as pessoas que forem fazer essa nova tv fossem todas como aqui, apaixonados, cultos, gentis, e não tecnocratas arrogantes cheios de vícios e quase nenhuma virtude verdadeira de dentro.

um beijo pra vocês, Tião.

Sebastião Maciel [lista roteirotelevisao] em 12 jan 2007. 


\section{Referências}

ALENCAR, Mauro. A Hollywood Brasileira. Rio de Janeiro: Senac, 2002.

ANDRADE, Roberta Manuela. O fascínio de Sherazade. São Paulo: Anna Blume, 2003.

ANG, I. Desesperaly searching the audiences. London: Routledge, 1991.

Watching Dallas: Soap Opera and the melodramatic imagination. London: Methuen, 1985.

BALOGH, Ana. Conjunções, disjunções, transmutações: da literatura ao cinema e á TV. São Paulo: Annablume, 1996.

O discurso ficcional na TV. São Paulo: Edusp, 2002.

BOURDIEU, Pierre. Razões práticas: Sobre a teoria da ação. Campinas, SP: Papirus, 1996 As regras da arte: gênese, estrutura e campo literário. 2ed. São Paulo: Companhia das Letras, 2005.

CALZA, Rose. Telenovela. São Paulo: Brasiliense, 1996.

CORNER, John. Debating culture: quality and inequality. In: CORNER, John. Studying media: problems of theory and method, p. 135-146. Edinburgh: Edinburgh University Press, 1998.

DANIEL FILHO. O circo Eletrônico. Rio de Janeiro: Zahar, 2001.

DICIONÁRIO DA TV GLOBO. Programas de Dramaturgia e entretenimento. Vol 1. Rio de Janeiro: Jorge Zahar, 2003.

FREIRE FILHO, João. Notas históricas sobre o conceito de qualidade na crítica televisual brasileira. Galáxia, abril, no 7, p. 85-110, 2004.

GERAGHTY, Christine. Aesthetics and quality in popular television drama. International Journal of Cultural Studies, vol. 6, nº 1, p. 25-45, 2003.

GORRESE, Gisela. O Amor nas Entrelinhas: As Cartas de Fãs de Telenovelas. Dissertação do Programa de Pós-Graduação em Psicologia Clínica - PUC/RJ, 2002.

HAMBURGER, Esther. O Brasil Antenado. Rio de Janeiro: Zahar, 2005.

JACOBS, Jason. Issues of judgement and value in television studies. International Journal of Cultural Studies, vol. 4, no 4, p. 427-447, 2001.

KLAGSBRUNN, Marta Maria e RESENDE, Beatriz (Org.). A telenovela no Rio de Janeiro: 1950 1963. Rio de Janeiro: CIEC/ECO/UFRJ-MIS, 1991.

MACHADO, Arlindo. A televisão levada a sério. 2ed. São Paulo: Senac, 2001.

MARTÍN-BARBERO, Jesús. De los medios a las mediaciones. Comunicación, cultura y hegemonia. México: Gustavo Gilli, 1987.

MATTELART, Michele e MATTELART, Armand. o carnaval das imagens: a ficção na TV. São Paulo: Brasiliense, 1989.

NOGUEIRA, Lisandro. O autor na televisão. São Paulo: Edusp; Goiânia: Editora UFG, 2002.

ORTIZ, Renato; BORELLI, Silvia Helena Simões; RAMOS, José Mário Ortiz. Telenovela: história e produção. São Paulo: Brasiliense, 1989.

PALLOTTINI, Renata. Dramaturgia de Televisão. São Paulo: Editora Moderna, 1998. 
PRIOLLI, G. e BORELLI, S. A Deusa Ferida. São Paulo: Summus, 2000.

SARLO, Beatriz. El Imperio de los Sentimientos. Buenos Aires: Catalogo Editora, 1985.

SOUZA, Maria Carmem. Reconhecimento e consagração: premissas para análise da autoria das telenovelas. In: GOMES, Itania e SOUZA. Maria Carmem (orgs.) Media e cultura. Salvador: PosCom/UFBA, 2002.

Telenovela e Representação social. Rio de Janeiro: e-papers, 2004.

Analisando a autoria das telenovelas. SOUZA, Maria Carmem (org.) Analisando telenovelas. Rio de Janeiro: e-papers, 2004b.

STAIGER, Janet . Authorship approaches. In: GERSTNER, David A \& STAIGER, Janet (org.). Authorship and Film. New York and London: Routledge, 2003, p. 27-57.

WEXMAN, Virginia Wright. Introduction. In: WEXMAN, Virginia Wright (org.), Film and Authorship. New Brunswick, New Jersey and London: Rutgers University Press, 2003, p. 1-18.

THOMAS, Lyn. Fans, feminism and "quality" media. London: Routledge, 2002. 